\title{
Cooperation needed to increase fertilizer efficiency
}

\section{Better use of nitrogen could provide more food and reduce the environmental impact.}

Sir - Your News Feature "Fertilized

to death" (Nature 425, 894-895; 2003)

deals with an extremely important issue:

reactive nitrogen and the need to increase the efficiency of nitrogen fertilizers.

James Galloway's work, as well as that of the IVL Swedish Environmental Research Institute, has pointed to significant environmental problems with excess reactive nitrogen.

Although environmental concerns about excess nitrogen are worth highlighting, the need to produce more food, more efficiently, in many parts of the world is even more urgent. Energy expert Vaclav
Smil estimates that approximately $40 \%$ of the world's dietary protein supply in the mid-1990s originated from fertilizer nitrogen (V. Smil Enriching the Earth 156-161, MIT Press; 2001). Agronomists and soil scientists throughout the world are working to make nitrogen use in farming more efficient for both food production and environmental reasons.

Although cutting back on fertilizer use might be a method to reduce the total load of reactive nitrogen in developed countries with excess food production capacity, it is not an acceptable solution in countries with malnourished people. The effect of increased food costs on people with low incomes in developed countries must also be considered. Efficiency improvements can help reduce nitrogen-fertilizer consumption if populations stabilize, and reduce its impact on the environment.

Ecologists, agronomists, environmental groups and industry must join to increase nitrogen-fertilizer efficiency for the benefit of everyone. Publications such as Nature should lead the way in building interdisciplinary support for this worthy goal. M. M. Alley

Crop and Soil Environmental Sciences Department, Virginia Tech, Blacksburg, Virginia 24061-0403, USA

\section{Fertilizer: complex issue calls for informed debate}

Sir - The News Feature "Fertilized to death" (Nature 425, 894-895; 2003) contains several inaccuracies about how reactive nitrogen is affecting ecosystems. As scientists working to understand these effects and to formulate methods for reducing them, we feel that the increase in reactive nitrogen is a serious and critical issue, which deserves informed discussion of the many complex issues involved.

First, although excess fertilizer use can have adverse environmental consequences, it contributes little to acid rain, whose principal causes are sulphur and $\mathrm{NO}_{x}$ emissions from fossil-fuel combustion by power plants and vehicles. Moreover, although ammonia emissions from agriculture contribute to high rates of nitrogen deposition in some forests, indirectly increasing soil acidity, these contributions are primarily from livestock, not from fertilizer.

Second, although the feature does state that it is not clear how different types of forest will respond to increased nitrogen deposition, it should be emphasized more clearly that the effects of increased nitrogen deposition on forest growth and mortality are highly variable and complex, and even the direction of response (increased or decreased growth) remains uncertain.

Third, it is important to recognize that almost half the nitrogen applied to crop fields is lost through aqueous run-off and atmospheric emissions (not run-off alone as stated in the article) and that the environmental impact of these two processes are very different. Aqueous losses of fertilizer nitrogen $(\sim 20 \%)$ are usually substantially less than atmospheric losses, although this run-off can still have serious environmental effects. Much of the loss to the atmosphere is through denitrification, which removes most of the reactive nitrogen from the ecosystem but can produce the greenhouse gas $\mathrm{N}_{2} \mathrm{O}$.

Finally, not all potential solutions to this problem need to be expensive or result in increasing the costs of agricultural production. In the United States, at least, current levels of agricultural production can be met by reducing excess application of synthetic nitrogen fertilizer, potentially saving farmers money.

Mark B. David ${ }^{\star}$, Gregory F. McIsaac*, Robert W. Howarth $\dagger$, Christine L. Goodale $\dagger$, Laurie E. Drinkwater

* Department of Natural Resources and Environmental Sciences, University of Illinois, Urbana, Illinois 61801, USA

$\dagger$ Department of Ecology and Evolutionary Biology, Cornell University, Ithaca, New York 14853, USA $\$$ Department of Horticulture, Cornell University, Ithaca, New York 14853, USA

\section{Fertilizer: no-till farming could reduce run-off}

Sir - In the News Feature "Fertilized to death” (Nature 425, 894-895; 2003), your reporter repeats a claim sometimes made in the medical literature that bluebaby syndrome (methaemoglobinaemia) is caused by excess nitrate in the tap water used to make up infant formula. However, it is nitrite, synthesized from nitrate by bacteria, that is the ultimate culprit in methaemoglobinaemia.

As humans cannot convert nitrate present in food or water to nitrite by themselves, the most likely source of bacterial contamination in cases of bluebaby syndrome is poor hygiene in making up infant formula. Fortunately, infants acquire an enzyme by the age of six months that protects them against nitrite poisoning.

It is true, of course, that excess nitrate levels in tap water are caused by fertilizer run-off and leaching into rivers, but it is surprising that there are far fewer cases of blue-baby syndrome in Europe (which has much higher levels of nitrate in tap water) than in the United States.

It is also worth noting that, despite hopes that organic farming would reduce nitrate in tap water, recent studies show that nitrate leaching from well-managed organic and conventional farms is effectively identical ${ }^{1,2}$.

A less-advertised, and cheaper, way of reducing nitrate levels in drinking water is 'no-till' agriculture. The plough has been used as a means of controlling weeds since the advent of agriculture itself. However, methods whereby crop material is mulched and left on the surface, and weeds controlled by herbicides, have been found to produce after several years a soil structure that is highly resistant to erosion, run-off and leaching.

Nitrate loss from a fertilized no-till field is approximately $12-20 \%$ of that from the equivalent ploughed field. Greater use of no-till, which is increasingly common in the United States but receives little encouragement from governments in Europe, would probably see nitrate levels in tap water return to those found before 1950 - about a quarter of current levels.

\section{Anthony Trewavas}

Institute of Cell and Molecular Biology, University of Edinburgh, King's Buildings, Edinburgh EH9 3JH, UK

1. Pickett, J. \& Goulding, K. House of Lords 16th report Organic Farming and the European Union 166 (HMSO, London, 1999). 2. Stopes, C. et al. Soil Use Management 18, 256-264 (2002).

\section{correspondence}

Contributions to Correspondence may be submitted to corres@nature.com. They should be no longer than 500 words, and ideally shorter. 